Abbreviated Key Title: Sch J Med Case Rep

ISSN 2347-9507 (Print) | ISSN 2347-6559 (Online)

Journal homepage: https://saspublishers.com

\title{
Cerebral Fat Embolism with No Lung Dysfunction: About A Case Report
}

H. El Mortaji", A. Chehboun, B. Boutakioute, M. Ouali Idrissi, N. Cherif Idrissi

\author{
Radiology department, Arrazi Hospital, CHU MED VI, Marrakech, Morocco
}

DOI: $10.36347 /$ sjmcr.2021.v09i04.023

| Received: 22.02.2021 | Accepted: 13.04.2021 | Published: 24.04.2021

*Corresponding author: H. El Mortaji

\section{Abstract}

Cerebral fat embolism syndrome is a variant of fat embolism syndrome characterized by a predominance of the neurological manifestations. It typically occurs in patients with bone fractures, usually long bones of the lower limb. The absence of pulmonary or dermatological manifestations on the initial presentation may delay the diagnosis of cerebral fat embolism. Magnetic resonance imaging is the recommended imaging modality for patients with suspected cerebral fat embolism. We report the case of a cerebral fat embolism with no lung dysfunction in a trauma patient.

Keywords: Cerebral fat embolism, trauma, MRI.

Copyright (C) 2021 The Author(s): This is an open-access article distributed under the terms of the Creative Commons Attribution 4.0 International License (CC BY-NC 4.0) which permits unrestricted use, distribution, and reproduction in any medium for non-commercial use provided the original author and source are credited.

\section{INTRODUCTION}

Fat embolism syndrome is a rare syndrome caused by embolization of fat particles into multiple organs including the brain. It typically manifests with the clinical triad of respiratory failure, unconsciousness, and petechial rash, usually occurring within 24 to $48 \mathrm{~h}$ of trauma [1]. Only few cases of cerebral fat embolism syndrom with no lung dysfunction have been reported [2].

\section{Case Report}

We report the case of a 80 year old male patient who presented to our department after sustaining road traffic accident with complaints of pain and deformity in the right leg. He had no history of loss of consciousness, vomiting, or convulsion. The initial assessment showed a deplaced fracture of both of the right tibia and fibula (figure 1) fixed with osteosynthesis materials within the 24 hours after his admission (Figure 2). 48 hours later, he presented a loss of consciousness. Physical examination revealed deep coma and petechial rash lesions. No respiratory signs were observed. The head CT scan performed at first did not show any lesions. However the MRI showed non circumscribed lesions within the periventricular white matter and the left thalamus hypointense in the T1 weighted images and hyperintense in the $\mathrm{T} 2$ weighted images with a restricted diffusion suggestive of an acute ischemia (Figure 3). It also showed a hyperintense nodular lesion in the $\mathrm{T} 2$ weighted images within the splenium of the corpus callosum (Figure 4).
The diagnosis of cerebral fat embolism was made on the basis of the clinical presentation and the MRI images.

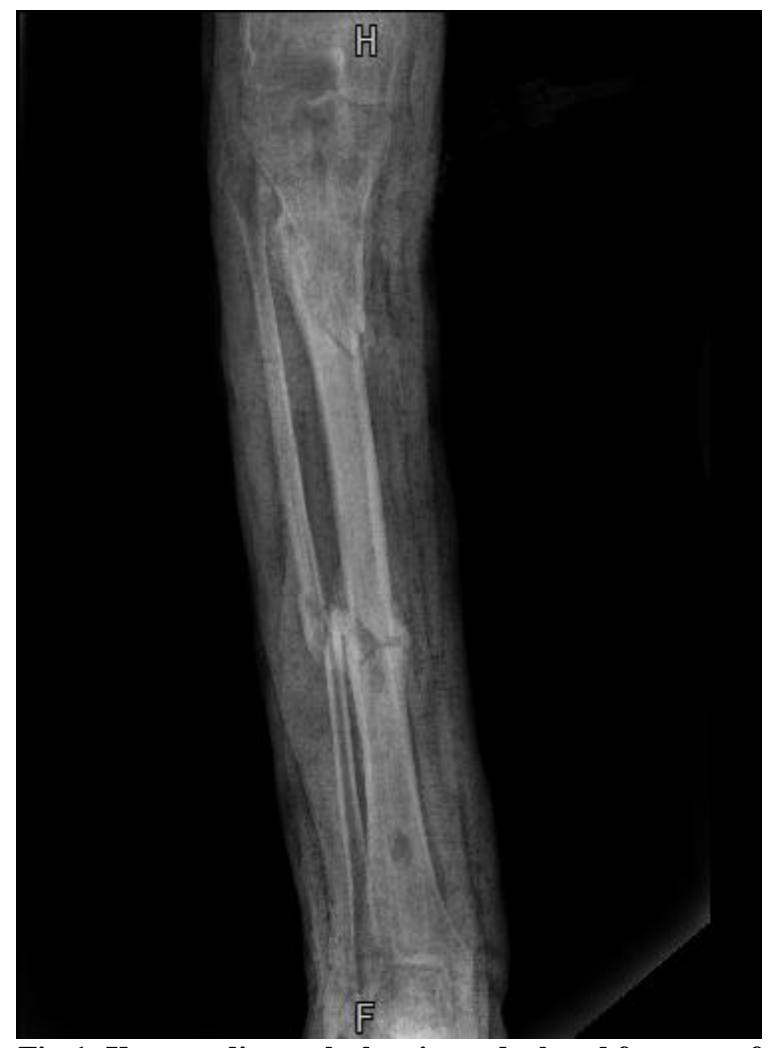

Fig-1: X-ray radiograph showing a deplaced fracture of the right tibial and fibular bones 


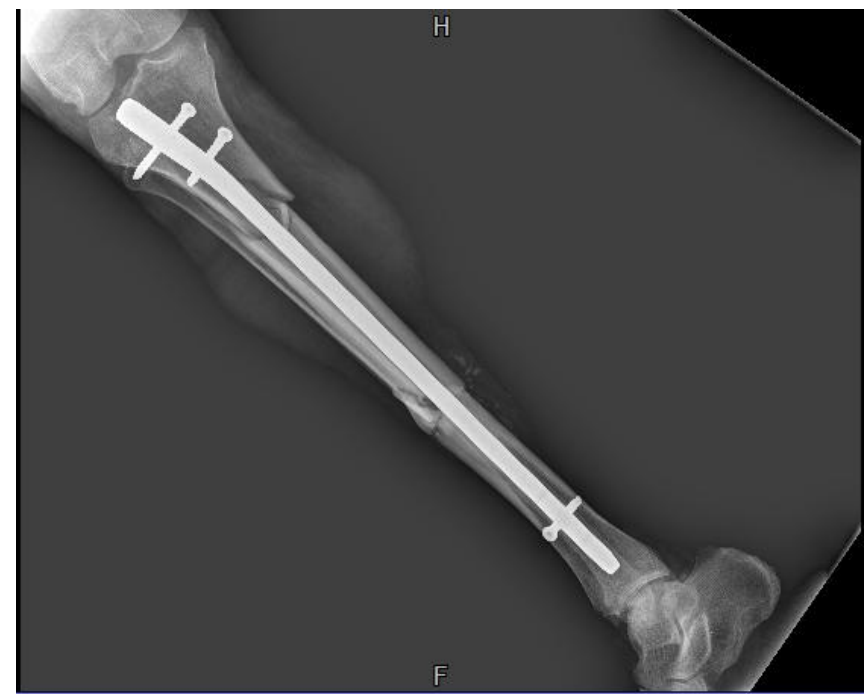

Fig-2: X-ray radiograph showing the post operative control

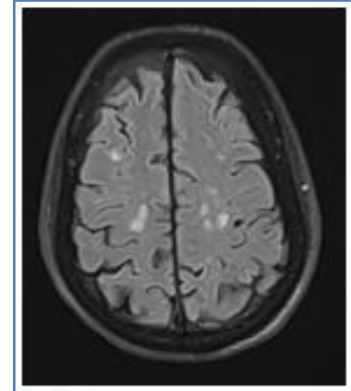

(a)

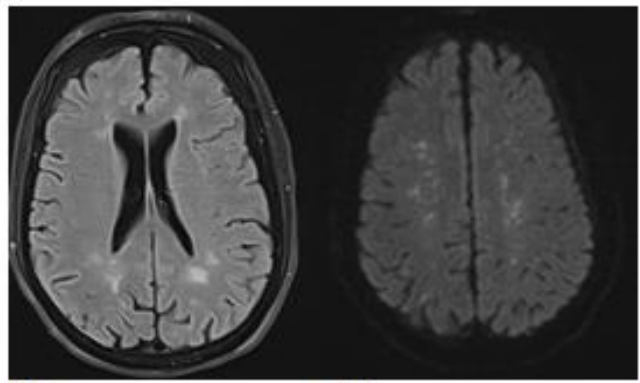

(c)

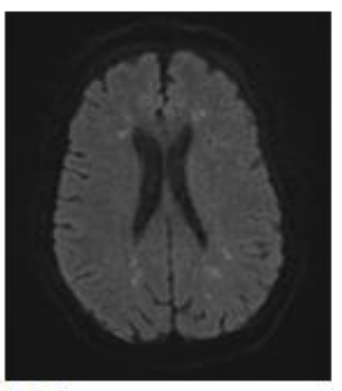

(d)

Fig-3: lesions within the periventricular white matter hyperintense in the T2 weighted images (a,b) and on the diffusion sequence $(\mathbf{c}, \mathrm{d})$

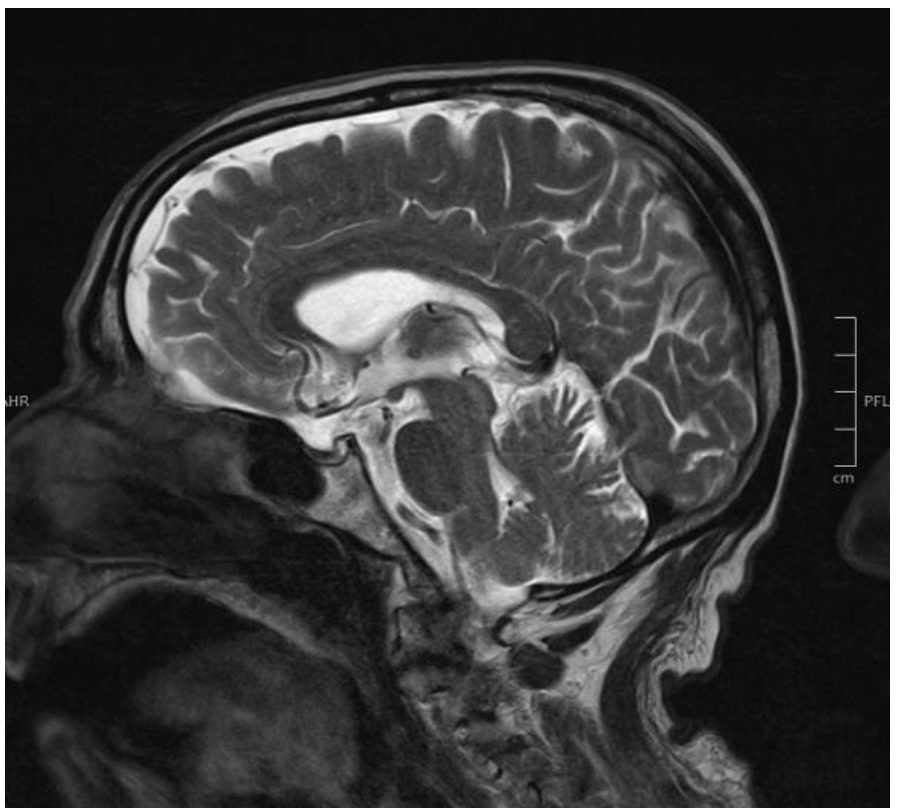

Fig-4: Nodular lesion within the splenium of the corpus callosum with hypersignal on the T2 weighted image

\section{Discussion}

Fat embolism syndrome remains a rare and life-threatening clinical diagnosis that has been reported in $0.5-3.5 \%$ of cases of traumatic long-bone fractures
[3], the cerebral involvement is even more uncommon [4].

The real pathogenesis of cerebral fat embolism is still not very clear. Normally embolus in the venous 
system of a lower extremity can migrate to the intracranial vessels only through pulmonary circulation. At first the emboli cause a lung fat embolism and then induce ischemia and hypoxia of the pulmonary circulation with a series of clinical disorders, such as difficult breathing and chest distress. In severe cases, it is life-threatening. Jacobsen and al reported that cerebral changes are seen in $86 \%$ of patients with fat embolism syndrome [5].

However, in our case the clinical presentation does not include pulmonary symptoms. Some authors have given the theory of few fat drop that can pass through the pulmonary capillaries or an open foramen ovale into systemic circulation and lodge in the cerebral vessels.

Cerebral fat embolism causes hypoxia. Then, abnormal metabolites are released. They affect the thalami and the sensory areas of the temporal lobe wich may cause hallucination. When the excitatory neurotransmitter depletes, patients become unconscious. This may explain why patients with cerebral fat embolism present a latent interval and are unconscious only $24 \mathrm{~h}$ after injury [6].

The typical symptoms of fat embolism include hypopnoea, cerebral dysfunction and skin petechiae. Patients with pure cerebral embolism present with apathy, lethargy, convulsion, coma and limb muscle tension appearing in the early period (12 h-3th day). Fever and scattered bleeding points in the chest as well as the neck are usually associated symptoms. Some patients have central facial palsy or hemiplegia and few have hallucinations [7]. In 1970, Gurd proposed the clinical diagnostic criteria for fat embolism [8]. However diagnostic criteria for cerebral fat embolism are not clear, and are mainly dependent on medical history, clinical manifestations and related examinations.

Undoubtedly, MRI has become the main diagnosis tool for cerebral fat embolism. The CT scan is not usefull for the diagnosis, but it is usually performed first to exclud a mental disorder which may be caused by other reasons [9].

At the acute stage, MRI shows diffuse areas of signal anomalies of the both white and gray matter, those are in hyposignal in T1-weighted images and in hypersignal in T2-weighted and diffusion images. It also shows areas of restricted diffusion that are due to cytotoxic edema, resulting from multiple microemboli. These lesions correspond to pale infarctions. The involvement of the splenium of the corpus callosum as it's the case of our patient has been described recently [2].

Other signal abnormalities of the white matter in hyper signal in T1 and T2 weighted sequences have been described and are related to hemorrhagic infarctions [10].

These changes on imaging seem to be closely linked to clinical severity and subsequent studies have been able to demonstrate their resolution by several weeks post insult. In some cases the follow-up with MRI will show either demyelination lesions or cerebral atrophy [11].

Once the cerebral fat embolism is encountered, prevention, early detection, and appropriate management are crucial. There are no specific treatment guidelines for cerebral fat embolism. Management of fat embolism seyndrome requires early immobilization of the fracture, symptomatic management of respiratory, cardiovascular, and neurological abnormalities [12].

Most patients with fat embolism syndrom show good recovery. Residual neurological deficits range from cognitive dysfunction, subtle personality changes to memory loss, and sometimes focal deficits. The mortality ranges from $5 \%$ to $15 \%$ and is usually secondary to pulmonary involvement rather than the cerebral lesions [1].

\section{CONCLUSION}

In case of diffuse or focal neurological symptoms following a bone fracture and normal CT scan images, MRI is undoubtedly the main tool that can make the diagnosis of cerebral fat embolism. Therefore early brain MRI in patients with neurological symptoms after trauma even in the absence of pulmonary and dermatological findings should be the goal.

\section{REFERENCES}

1. Mellor A, Soni N. Fat embolism. Anaesthesia. 2001 Feb;56(2):145-54.

2. Parizel PM, Demey HE, Veeckmans G, Verstreken F, Cras P, Jorens PG, De Schepper AM. Early diagnosis of cerebral fat embolism syndrome by diffusion-weighted MRI (starfield pattern). Stroke. 2001 Dec 1;32(12):2942-4.

3. Wang NN, Panda N, Hyun JS, Barounis D, Weiser TG. Cerebral fat embolism in a trauma patient with captured imaging of echogenic emboli in the inferior vena cava. Journal of Medical Ultrasound. 2016 Dec 1;24(4):162-5.

4. Eguia P, Medina A, Garcia- Monco JC, Martin V, Monton FI. The Value of Diffusion- Weighted MRI in the Diagnosis of Cerebral Fat Embolism. Journal of Neuroimaging. 2007 Jan;17(1):78-80.

5. Jacobson DM, Terrence CF, Reinmuth OM. The neurologic manifestations of fat embolism. Neurology. 1986 Jun 1;36(6):847-.

6. Zhou Y, Yuan Y, Huang C, Hu L, Cheng X. Pathogenesis, diagnosis and treatment of cerebral 
fat embolism. Chinese Journal of Traumatology. 2015 Apr 1;18(2):120-3.

7. Gleich SJ, Hannon JD. Cerebral fat embolism syndrome from penetrating trauma: a rare causeand-effect.

8. Gurd AR, Wilson RI. The fat embolism syndrome. The Journal of bone and joint surgery. British volume. 1974 Aug;56(3):408-16.

9. Suh SI, Seol HY, Seo WK, Koh SB. Cerebral fat embolism: susceptibility-weighted magnetic resonance imaging. Archives of neurology. 2009 Sep 1;66(9):1170-.

10. Ryu CW, Lee DH, Kim TK, Kim SJ, Kim HS, Lee JH, Choi CG, Suh DC. Cerebral fat embolism: diffusion-weighted magnetic resonance imaging findings. Acta Radiologica. 2005 Jan 1;46(5):52833.

11. Nissar Shaikh ZM, Ghuori SI, Chanda A, Ganaw A, Zeeshan Q, Ehfeda M, Belkhair AO, Zubair M, Kazi ST, Momin U. Correlation of clinical parameters with imaging findings to confirm the diagnosis of fat embolism syndrome. International journal of burns and trauma. 2018;8(5):135.

12. Aggarwal R, Pal S, Soni KD, Gamangatti S. Massive cerebral fat embolism leading to brain death: a rare presentation. Indian journal of critical care medicine: peer-reviewed, official publication of Indian Society of Critical Care Medicine. 2015 Nov;19(11):687. 